\title{
Sri Lankan Twin Registry
}

\author{
Athula Sumathipala', Sisira Siribaddana ${ }^{2}$, Nimali De Silva ${ }^{3}$, Devaka Fernando ${ }^{3}$, Nihal Abeysingha ${ }^{3}$, \\ Rohana Dayaratne ${ }^{4}$, Deepthi De Silva ${ }^{5}$, Narada Warnasuriya ${ }^{3}$ and Mathew Hotopf ${ }^{6}$ \\ 'Section of Epidemiology, Institute of Psychiatry, Kings College, University of London, UK \\ ${ }^{2}$ Sri Jayewardenepura General Hospital, Sri Lanka \\ ${ }^{3}$ Faculty of Medical Sciences, University of Sri Jayewardenepura, Sri Lanka \\ ${ }^{4}$ General Hospital, Ratnepura, Sri Lanka \\ ${ }^{5}$ Faculty of Medicine, University of Keleniya, Sri Lanka \\ ${ }^{6}$ Department of Psychological Medicine, Institute of Psychiatry, Kings College, University of London, UK
}

\begin{abstract}
Sri Lanka is an island with genetic diversity between the five $\checkmark$ main population groups. Our twin registry is the first in the developing world. Initially, we established a volunteer cohort of 4600 twin pairs through a competition advertised in the media. In addition, we have volunteer cohorts, birth registration-based cohorts through hospitals, and community-based cohorts. There is also a nationwide population-based younger twin cohort (1992-1997) traced through the Department of Birth and Death Registration. Additionally, we have adapted a Zygosity determination questionnaire and validated it. Establishing ethical guidelines for twin research was a priority because the field of bio-ethics is at an early stage of development in Sri Lanka. These guidelines were from a developing world perspective. A sister organization, the Multiple Birth Foundation, was formed to cater to twins and their special needs and to represent their interests, and several branches have been formed. We intend to build capacity by establishing a genetic lab and through crosscultural collaboration. Our vision is to establish a multidisciplinary research foundation. Based on our research findings, we plan to build services to cater to needs of twins by working with professionals, statutory services and government policy makers.
\end{abstract}

Anthropologically, Sri Lanka is an interesting island, with genetic diversity between the five main populations due to the contribution of ancestral and immigrant elements of European and Asian origin. In this scenario, the many research projects in human biology that have been carried out have always had to contend with and at times confront a perennial problem. That being the determination of whether the human biological variation one encounters, is a direct impact of the genetic constitution or the influence of a wide spectrum of environmental forces that control the final outcome of a physiological process, a parameter or a stage of development (Jayesekara, 1997).

The Sri Lankan Twin Registry is the first to be established in the developing world (Sumathipala et al., 2000a). Based on a proposal by Athula Sumathipala, a working group was initially formed in 1996 by Athula Sumathipala, Devaka Fernando, Sisira Siribaddana and Nihal Abeysingha. Ethical approval was obtained from the Ethical Committee of the Faculty of Medicine, Colombo, and the Institute of Psychiatry, London.

We had many obstacles to overcome compared to the twin registries in the developed world. The acquisition of basic knowledge on the subject was vital, but relevant books and journals were scarce and the concept of twin research was new. Contribution of the Institute of Psychiatry, London, was crucial to the initiation of the registry.

Being a new initiative, obtaining funding was the greatest obstacle as only less than $10 \%$ of research funds are spent on the diseases that account for $90 \%$ of the global disease burden (Lee \& Mills, 2000). Without prior work in twin research and without credentials, obtaining funding from international research charities was impossible and there was no opportunity for local research funding. However, we launched a letter-writing campaign for support from business organizations. Two leading national newspapers in Sri Lanka offered free newspaper advertisements for a twin competition. We established the main volunteer cohort through this competition (Sumathipala et al., 2000a)

\section{Ethical Issues}

Establishing the twin register and conducting genetic research demanded the development of ethical guidelines as a priority since the field of bio-ethics was at an early stage of development in Sri Lanka (Simpson, 2001). Our guidelines were based on the principles of (Sumathipala \& Siribaddana, 2001):

1. International collaborations for mutually beneficial research based on an agenda set by the developing world.

2. Capacity building in the developing world through research projects.

3. Third party ombudsman to ensure freely given informed consent.

4. Protecting the national ownership to prevent undue commercial exploitation of research.

5. Importance of a statutory framework robust enough to protect public interest but balanced enough to allow new developments.

These ethical guidelines were widely distributed for discussion to establish a consensus (Sumathipala $\&$ Siribaddana, 2002).

Address for correspondence: Athula Sumathiapala, Section of Epidemiology, Institute of Psychiatry, Kings College, University of London, 33 Ripley Road, Ilford, Essex IG3 9HA UK. Email: spjuats@iop.kcl.ac.uk 


\section{Twin Statistics}

We have several twin cohorts and they are mainly of three types: volunteer, birth register-based and community survey-based.

\section{Main Volunteer Cohort}

The volunteer registry has been described in detail elsewhere (Sumathipala et al., 2000a.). A summary of the statistics is given in Table 1.

Bandarewela volunteer cohort. This smaller cohort consists of 65 twin pairs born between 1963-1995, mainly school children. There are $24 \mathrm{MM}, 18 \mathrm{FF}$ and $17 \mathrm{MF}$ pairs. This shows that schools are a potential source of recruitment of younger twins.

\section{Birth Register Based Cohorts}

The Sri Jayewardenepura Hospital cohort consists of 433 twin pairs, 11 triplets and one quadruplet born between 1985-1997 (Sumathipala et al., 2001). We also have similar cohorts from two leading maternity hospitals. These are two separate cohorts from two main maternity hospitals in Colombo born between 1954- 1970. These were older twins detected through the Divisional Secretariat. Although 310 twin pairs were identified through birth records, only 53 twin pairs were traced. Using birth records to trace younger twins was feasible, but many problems were encountered for older twins (Sumathiapala et al., in press). Feasability studies show that the use of several different strategies to establish a population-based registry can be beneficial.

A nationwide population-based younger twin cohort (1992-1997): Cohort traced through the Registrar General Department of Birth and Death Registration. This cohort of twins, which is a population-based cohort, was traced through the Registrar General of the Births and Death Registration Department. Between 2500-3500 twins were born each year (De Silva, 2002).

Nationwide population-based prospective birth cohort (2002). The Registrar General of the Births and Death Registration Department has officially agreed to provide us with the details of multiple births on a monthly return basis from 2002. This is expected to be around 200-300 twin pairs a month.

\section{Community Based Cohorts}

We carried out three community surveys to look into the feasibility and effectiveness of establishing a populationbased register including older twins. The first community-based cohort consisted of 37 pairs (10 MM, $11 \mathrm{FF}$ and $13 \mathrm{MF}$ pairs; Sumathipala et al., 2001). We also carried out two more community surveys in two of the

Table 1

Volunteer-based Registry Statistics

\begin{tabular}{lcccc}
\hline & $\begin{array}{c}\text { Same sex } \\
\text { Male }\end{array}$ & $\begin{array}{c}\text { Same sex } \\
\text { Female }\end{array}$ & $\begin{array}{c}\text { Different } \\
\text { sex }\end{array}$ & Total \\
\hline Twin pairs & 1564 & 1885 & 1153 & 4602 \\
Triplets & 17 & 31 & 42 & 90 \\
Quadruplets & - & - & 2 & 2 \\
\hline
\end{tabular}

smallest administrative units in Colombo district. A Key Informant was used, which proved to be a costeffective method to trace twins. Door knocking also proved effective to obtain a representative community sample. This recruitment strategy will now be extended to a twin study with a larger population-based sample on common mental disorders, alcohol and suicide as well as a study on osteoporosis.

From the data available so far the following twining rates were witnessed:

1. Island-wide birth registration data for 1992 gives a rate of 17.9 twins per 1000 registered births.

2. An average of 17.2 twins per 1000 deliveries in 1997 for all state institutions where deliveries have taken place.

3. 18.92 twins per 1000 deliveries for the period of 1985-1997 in a general hospital in Colombo.

4. 29.95 twins per 1000 deliveries for the period of 1954-1970, in a leading maternity hospital in Colombo.

5. In one suburban community survey, carried out by medical students, a rate of 6.5 twins per 1000 residents was obtained. In another community survey the infrastructure of the National Census 2001 was used and we obtained a rate of 24.8 twins per 1000 residents. Therefore, the second estimate was more reliable and comprehensive.

\section{Work Carried Out with Twins}

The work we have undertaken has been preliminary work required for establishing a twin registry for research.

\section{Zygosity Determination}

We have carried out a preliminary validation and adaptation of a zygosity questionnaire by Ooki, Yamada and Asaka (Sumathiapala et al., 2000b)

\section{Higher Degrees}

Two projects are underway by two MSC students, one on the antenatal and postnatal complication of twin pregnancies and another on cognitive development of twins between the ages of $0-3$ years. Another postgraduate student has undertaken a study on genetic and environmental influences on smoking.

\section{Qualitative Work}

We carried out a qualitative study using focus groups on adverse life events and social deprivation as risk factors for common mental disorders.

\section{Tracing the Pedigrees of the Volunteer Twin Cohort}

A postal survey was administered to the twins in the volunteer cohort to study the twining rates in their immediate and extended families for up to 4 generations. We have received responses from about 1646 registrants. 886 (53.83\%) had a history of twinning in the families of index twins.

\section{A Multiple Birth Organization}

This organization was formed to support multiples and their families. The objectives of the organization are to raise awareness of the unique issues faced by multiples and their 
families, and to build services to cater to their needs by working with professionals, statutory services and policy makers. We have so far formed 5 branches.

\section{Publicity}

A web site is our main link to the outside world. (http://www.infolanka.com/org/twin-registry/). We have also published two brochures and produce a regular news bulletin for the twins and professionals.

\section{$\overline{\text { Prospects for Collaboration }}$}

We would like to invite and encourage international researchers to join in mutually beneficial collaborations. The potential projects are visceral obesity, twin studies on alcohol use, abuse and addiction, prospective zygosity determination by placentation in twins and cognitive development of younger twins.

\section{Capacity Building}

Through crosscultural collaboration we would like to build our capacity in all areas needed to carry out twin research. Establishing a genetic laboratory and service will be one of the essential components.

\section{Strengths and Weaknesses}

Sri Lanka is a country with a genetic diversity that is largely unexplored. Sri Lanka has an accuracy of $98 \%$ in birth and death registration. Establishing a nationwide, comprehensive, population-based twin registry is possible because twins can be traced through hospital and birth registration records and also through community surveys. Therefore, larger population-based samples could be used to carry out studies. In addition, we have a high literacy rate and a good primary health care system.

As a registry in its infancy we lack adequate expertize in twin research methodology, laboratory facilities and an ethical framework.

\section{$\overline{\text { Our Vision }}$}

Our vision is to establish a multidisciplinary research foundation, to carry out research that will contribute to improving quality of life and to achieving health equity. Based on our research findings, we plan to build services to cater to multiples' needs by working with professionals, statutory services and government policy makers.

\section{Acknowledgments}

We received an international collaborative research initiation grant from the Wellcome Trust.

\section{References}

De Silva, N., Sumathipala, A., Fernando, D. J. S., Abeysingha, M. R. N., Siribaddana, S. H., Dayaratne, D. A. R. K., De Silva, D. et al. (2001). Early report on the availability of island wide twin data in the central birth registration department. (Abstract). Twin Research, 4, 179.

Jayasekera, R. (2002). Sri Lankan Twin Registry website. [online] http://infolanka.com/org/twin-registry/

Lee, K., \& Mills, A. (2000). Strengthening governance for global health research. British Medical Journal, 321, 775-776.

Simpson, B. (2001). Ethical regulation and the new reproductive technologies in Sri Lanka: Perspectives of the ethics committee members. Ceylon Medical Journal, 46, 54-57.

Sumathipala, A., Fernando, D. S. J., Siribaddana, S. H., Abeysingha, M. R. N., De Silva, N., Dissanayake, V. et al. (2000a). Establishment of a National Twin Register in Sri Lanka. Twin Research, 3, 202.

Sumathipala, A., \& Siribaddana, S. H. (2001). Bridge the existing divide between North- South bio-ethical philosophies. [online] eBritish Medical Journal, http://www.bmj.com/letters, April 19, 2001.

Sumathiapala, A., \& Siribaddana, S. H. (2002). Revisiting "freely given informed consent" in relation to the developing world: Role of an ombudsman. Manuscript submitted for publication.

Sumathipala, A., Siribaddana, S. H., De Silva, N., Abeysingha, M. R. N., Sivayogam, S., \& Fernando, D. J. S. (2001). Feasibility of using birth records for recruiting younger twins to establishment of a population based register in Sri Lanka. Twin Research, 4, 459-463.

Sumathipala, A., Siribaddana, S. H., De Silva, N., Abeysingha, M. R. N., Fernando, D. J. S., Dayaratne, D. A. R. K. (in press). Challenges in recruiting older twins for the Sri Lankan twin registry. Twin Research.

Sumathipala, A., De Silva, N., Siribaddana, S. H., Fernando, D. S. J., \& Abeysingha, M. R. N. (2000b). Cross cultural adaptation and preliminary validation of a zygosity determination questionnaire for Sri Lanka. Twin Research, 3, 205-212. 